\title{
Percutaneous Transluminal Angioplasty of Infrapopliteal Arteries in Patients with Intermittent Claudication: Acute and Six-Month-Results
}

\author{
Desur Samancı ${ }^{1}$, $\odot$ Yılmaz Önal ${ }^{2}$ \\ ${ }^{1}$ Department of Radiology, Haydarpasa Sultan Abdulhamid Han Training and Research Hospital, Istanbul, Turkey \\ ${ }^{2}$ Department of Radiology, Fatih Sultan Mehmet Training and Research Hospital, Istanbul, Turkey
}

\begin{abstract}
Introduction: Critical leg ischemia represents the final stage of atherosclerotic peripheral arterial disease (PAD). Patients affected by critical leg ischemia are the most complex subset of PAD and typically have chronic pathological consequences of hypertension, hyperlipidemia, diabetes and renal failure.

Methods: In this study, we evaluated the early and sixth-month outcomes of percutaneous transluminal angioplasty (PTA) in patients with stenosis or occlusion at the infrapopliteal level. Only one leg was treated in one session. None of the patients received infrapopliteal stents, and only balloon angioplasty was performed.

Results: In our study, 41 vessels with a total of 48 lesions in 31 patients were treated. The primary patency rate of the vascular segments treated at follow-up was $72.9 \%$.

Discussion and Conclusion: In PTA, failure in the procedure and loss of patency are the main therapeutic challenges to be solved. Large-scale, multicenter, prospective studies that systematically evaluate existing infrapopliteal treatment methods are needed to develop contemporary, proven treatment standards.

Keywords: Intermittent claudication; percutaneous transluminal angioplasty; peripheral artery disease.
\end{abstract}

$\mathrm{P}$ eripheral artery disease (PAH) and critical leg ischemia often cause a clinical picture due to the involvement of the areas perfused by lower extremity artery areas, and patients may have an intermittent limping (intermittent claudication) described in the calf region. The complaint of intermittent limping is related to the patients feeling is chemic pain due to arterial circulation within certain walking distance, which cannot respond to the metabolic needs of the muscles. The pain is relieved with rest, and the same pain recurs again at the same distance after starting walking again ${ }^{[1]}$. Intermittent claudication is one of the mildest manifestations of $\mathrm{PAH}$, and its prevalence is approximately $5 \%$ in men over 50 years of age ${ }^{[2]}$.

The aging of the population in western societies suggest that the prevalence of this situation will increase in the coming years. Revascularization of the occluded vessel is required to improve symptoms, and various treatment strategies have been proposed, such as exercise, surgical interventions, percutaneous transluminal angioplasty (PTA) and stent implantation. Since surgical treatments increase

Correspondence (iletişim): Cesur Samancı, M.D. Haydarpasa Sultan Abdulhamid Han Egitim ve Arastirma Hastanesi,

Radyoloji Anabilim Dali, Istanbul, Turkey

Phone (Telefon): +90 5320151886 E-mail (E-posta): cesursamanci@gmail.com

Submitted Date (Başvuru Tarihi): 01.07.2019 Accepted Date (Kabul Tarihi): 08.10.2019

Copyright 2020 Haydarpaşa Numune Medical Journal

OPEN ACCESS This is an open access article under the CC BY-NC license (http://creativecommons.org/licenses/by-nc/4.0/) 
morbidity and length of hospital stay, endovascular treatment methods are more frequently preferred today. Infrapopliteal interventions were firstly described 30 years ago by Dotter and Judkins; Grüntzig and Hopff ${ }^{[3,4]}$. Since then, percutaneous interventions have been widely used for the treatment of PAH.

PTA and stent implantation has been shown to be effective in the treatment of iliac and femoropopliteal occlusions, even in complicated and chronic lesions ${ }^{[4]}$. With the use of low- profile catheters and hydrophilic directable guide wires, PTA is applied more and more frequently, even under the knee, with higher success rates. Good results have been obtained, especially in patients with surgical comorbidity and in cases with critical ischemia in the lower extremit$y(\text { ies })^{[6-9]}$. However, in studies conducted in the infrapopliteal region, significant heterogeneity was observed in most of the results ${ }^{[10]}$. In some studies ${ }^{[11,12]}$, while 1-year patency was around $30-40 \%$, in some studies ${ }^{[13,14]}$, this rate was found as $70-80 \%$ in some others.

In this study, the efficacy of PTA, which is an endovascular approach in the treatment of patients with intermittent claudication, was evaluated in infrapopliteal arteries.

\section{Materials and Methods}

\section{Patients}

Our study was approved by the ethics committee and informed consent was obtained from the patients. The files, epicrises, and ankle-brachial index (ABI) measurements of 31 patients who underwent PTA for the complaints of claudication in the interventional radiology unit of our hospital were evaluated retrospectively from the archives of our hospital, and conventional angiography images of these patients obtained before and after the intervention retrieved from the PACS system were evaluated. Thirty-one patients with Fontaine grade $\mathrm{Ilb} \mathrm{Cl}$ complaints were included in this study.

Only one leg of the patients was treated in one session. Infrapopliteal stenting was not performed in any patient and only balloon angioplasty was inserted. Conventional angiography was performed on these patients before and after the intervention, and ABIs were calculated before and after the procedure. According to the Rutherford classification, 23 patients $(74.1 \%)$ had moderate $\mathrm{Cl}$ (Rutherford category 2) and eight patients (25.8\%) had severe $\mathrm{Cl}$ (Rutherford category 3). Rutherford classification is divided into seven categories, from 0 to 6 . While determining the category of the patient, clinical data and some objective tests were used.
In category 0 , the patient is asymptomatic. In categories 1, 2 and 3, mild, moderate, severe leg pains are felt, respectively; in category 4 , pain during rest is felt. In category 5 , small tissue loss, and diffuse foot ischemia are detected. In category 6, major tissue loss is detected, and functions of the leg are not recoverable ${ }^{[15]}$. As a result, unilateral interventions were performed in $27(87 \%)$ and bilateral interventions in four patients (12.9\%). A total of 48 lesions were treated in 31 patients involving peroneal arteries (PA) $(n=10)$, anterior tibial arteries (ATA) $(n=19)$ and posterior tibial arteries (ATP) $(n=12)$ (Fig. 1).

\section{Procedure Applied and Evaluation of the Lesion}

In most of the patients, dual antiplatelet (100 mg aspirin and $75 \mathrm{mg}$ clopidogrel) therapy is currently used before the procedure, and patients who did not receive this treatment, premedication with dual antiplatelet was practiced one week before the procedure. During the procedure, a bolus dose of 5,000 IU heparin was administered. Six patients with kidney failure received $2500 \mathrm{IU}$ heparin. In patients with bilateral disease, interventions were carried out separately within a few days. In six patients (19.3\%), the procedure was performed by inserting a long sheath into the contralateral leg and advancing it into the leg to be treated. Contralateral access was preferred in two of these six patients, because of the presence of a lesion in the proximal SFA and high-lying bifurcation in four of them.

In 25 (80.6\%) patients, the procedure was carried out through direct antegrade access. For stenotic lesions, a 0.018 Teflon coated guide wire (Connect, Abbott Vascular) with a steerable soft and atraumatic tip was used. In completely

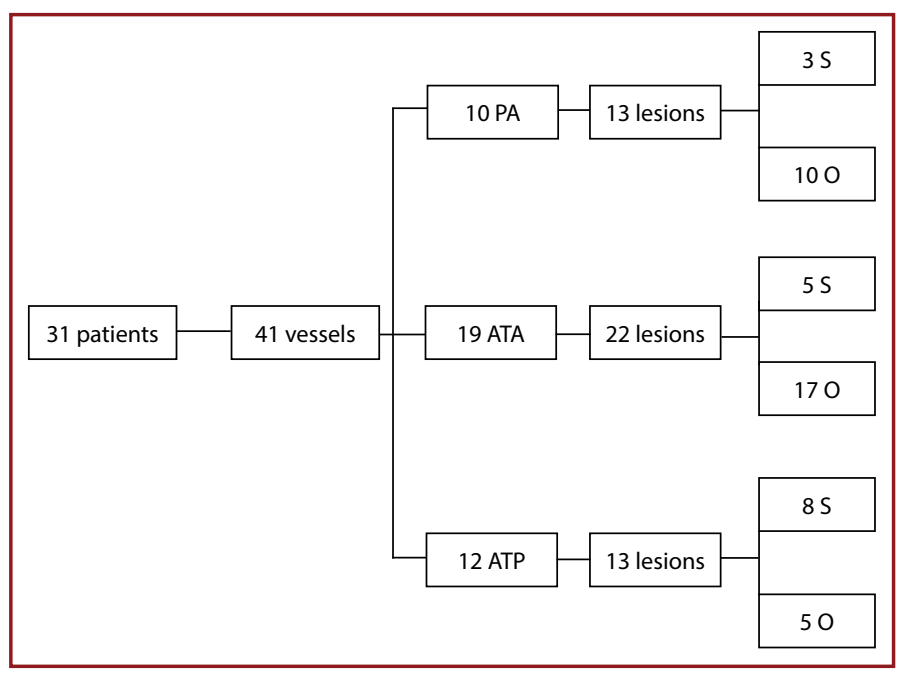

Figure 1. Vascular segments treated, number of lesions, and distribution of lesion types. O: occlusions; S: stenosis; ATA: anterior tibial artery; ATP: posterior tibial artery; PA: peroneal artery. 
clogged arteries, a guide wire with a hydrophilic tip (V-18 Control Wire $0.018,300 \mathrm{~cm}$; Boston Scientific, Maple Grove, $\mathrm{MN}$ ) was preferred. The first passage through the lesion under fluoroscopy was realized either with a multi-purpose diagnostic catheter (4 Fr, $125 \mathrm{~cm}$; Cordis, Miami Lakes, FL) or a hydrophilic support catheter (Navicross, $4 \mathrm{Fr}, 100 \mathrm{~cm}$, straight or angulated; Terumo, Miami, FL). After negotiating the guide wire beyond the lesion, contrast substance was delivered through the lumen of the multi-purpose catheter, and images were obtained to confirm that the catheter is not inserted into the subintimal layer or slipped into extravascular space.

After confirming that the catheter was inside the vein, all lesions were dilated for two minutes at 6-10 atm pressures using a low- profile balloon catheter (Pacific Plus PTA Catheter OTW 0.018) with a diameter of 2-3 mm. Procedural success was defined based on the image taken immediately after angioplasty that demonstrated a sufficient antegrade flow and less than $30 \%$ (visually) luminal stenosis. After the procedure, the vascular sheath was removed and manual compression was performed at the entry site. The patients were then discharged with a prescription of dual antiplatelet medication.

The patients were called for control at the 6 th month after the intervention. At follow-up, less than $50 \%$ of the luminal stenosis was evaluated as patency. Control examinations were performed with clinical evaluation, Doppler USG and $A B I$ measurements. Five patients applied to us with clinical complaints before the $6^{\text {th }}$-month control visit. The patients who had a vascular segment narrower than $50 \%$ in Doppler USG and/or in whom a postprocedural decrease in ABI measurements was detected were reoperated. Reinterventions were not included in the statistical analysis and study.

\section{Results}

Forty-one vessels with a total of 48 lesions in 31 patients were treated (Fig. 1). Thirty-four vascular occlusions (70.8\%) and 14 stenotic segments (29.1\%) were detected. Technical success was achieved by negotiating the lesion by the guide wire in all stenotic segments and recanalization was performed (Fig. 2). In seven (20.5\%) of 34 cases of occlusions, occlusive lesions could not be negotiated by guide wire. The general characteristics of the patients and lesions are indicated in the table. Technical success was achieved in 41 (85.4\%) of the 48 lesions in 31 patients included in this study, while seven occlusive lesions (14.6\%) could not be negotiated with a guide wire.

In the same session, additional treatment was required in

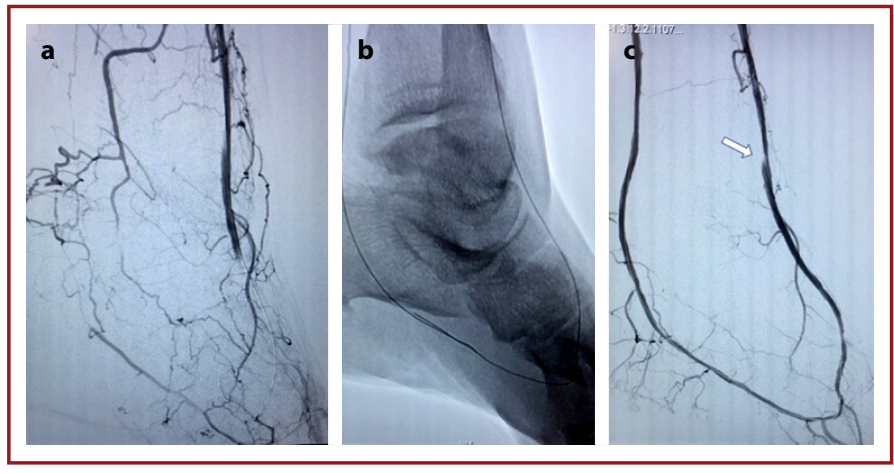

Figure 2. Selective image obtained from anterior tibial artery, completely occluded distal segment of ATA, DPA and anterior pedal arch are seen. However lateral pedal arch is perfused fully through collaterals (a). Patency of PTA was achieved through antegrade approach in a patient whose distal segment of ATP was also occluded. Control image (b) obtained following retrograde angioplasty of the arch through ATA (b) reveals complete recanalization of ATA, ATP, ADP, and pedal arch (c). Dissection (white arrow) distal to ATA which allowed blood flow was not intervened.

two patients during interventions performed for the superficial femoral and/or popliteal artery above the knee. There were no major side effects associated with the procedure, i.e., death, amputation, or emergency surgery. Small hematoma formed at the puncture site in two (6.4\%). patients. $\mathrm{ABI}$ measurements were performed in the patients after the procedure. In Wilcoxon analysis, the mean $\mathrm{ABI}$ values at rest increased significantly from $0.70 \pm 0.14$ to $0.77 \pm 0.13(p<0.001)$. Considering the Rutherford categories of patients before and after the procedure, improvement of two Rutherford categories was achieved in two patients (6.4\%), while one Rutherford category improvement was obtained in 18 (58\%) patients. However, Rutherford category remained unchanged in 11 (35.4\%) patients. In other words, in this group of patients, an increase in intermittent limping distance and a decrease in pain were considered as clinical improvement.

Thirty-five limbs of 31 patients were reevaluated six months later. Eighteen of 31 patients were asymptomatic. At follow-up, patency was evaluated as less than $50 \%$ luminal stenosis. At follow-up visits, primary patency rate of $72.9 \%$ was detected in the vascular segments treated. In 13 vessels, any vascular patency was not observed.

Five patients who presented with their first complaints before six-month-control visits and had more than $50 \%$ restenosis in the vessel that had been intervened as detected on Doppler US were reevaluated.

In these reevaluated patients, restenosis was observed with Doppler USG in five vessels, which were treated with procedural success. However, these additional procedures were not included in this study and analysis. When these five pa- 
tients came for control in the 6th postprocedural month, vascular patency was not observed in the evaluation and these lesions were included in the group without patency. These five patients, whose vascular patency could not be achieve$\mathrm{d}$,had a history of uncontrolled diabetes and hypertension.

\section{Discussion}

Critical leg ischemia represents the final stage of atherosclerotic PAD. Patients affected by critical leg ischemia are the most complex subset of PAD and typically carry chronic pathological consequences of hypertension, hyperlipidemia, diabetes, and kidney failure. They are characterized anatomically at the infrapopliteal level with widespread multi-segmental and multivessel involvement.

Any clear-cut consensus was not accepted by everyone for percutaneous revascularization to be performed in these patients with complex lesions ${ }^{[16]}$. Currently, PTA is the most accepted treatment and is frequently used for lesions at the infrapopliteal level ${ }^{[17]}$. Although there are not much data in the literature about PTA outcomes, we know from various studies that infrapopliteal PTA is safe and can be performed with high technical success ${ }^{[18,19]}$. Krakenberg et al. ${ }^{[20]}$ performed PTA for infrapopliteal occlusions in 78 patients with claudication and found the primary technical success rate to be almost $90 \%$, and the complication rate as $5.8 \%$. In their study, Kok et al. ${ }^{[21]}$ found their overall technical success rate as $75 \%$, lower extremity recovery rates as $77 \%$ in one year and $65 \%$ in three years.

In our opinion, the reason why these rates are relatively lower than those reported by Krakenberg et al. may be because many lesions in the study included prevalently seen calcific, multiple long- segment occlusions. During angioplasty performed for knee vessels, complications, such as flow-inhibiting dissection and distal embolism related to plaque rupture, may be encountered. In our study, our technical success rate was $85.4 \%$, and our complication rate was 9.6 percent. These complications were limited to small hematomas developed at the puncture site in two patients. In one patient, dissection developed after angioplasty performed distal of ATA was observed. However, any intervention was not performed because it did not occlude blood flow. $\mathrm{ABI}$, which is the ratio between systolic pressures of ankle and arm, is a fast and easy method and has been used in practice for many years to confirm the diagnosis and seriousness of PAD in the legs ${ }^{[22]}$. However, $A B I$ is also an indicator of diffuse atherosclerosis because low levels of $A B I$ have been associated with higher rates of accompanying coronary and cerebrovascular disease and the presence of cardiovascular risk factors. One of the parameters we evaluated in our study was $A B I$. The mean $A B I$ measurement increased from $0.70 \pm 0.14$ before the procedure to $0.77 \pm 0.13$ after the procedure.

We also examined Rutherford categories of patients before and after the procedure. Improvement of 2 Rutherford categories was detected in $6.4 \%$ of the patients, while $58 \%$ of the patients demonstrated one Rutherford category improvement. However, Rutherford categories remained unchanged in $35.4 \%$ of the patients.

Given that many factors act in combination and affect the treatment outcomes, physicians experience great difficulties in evaluating the data of the patients undergoing PTA. Mustapha et al. published a meta-analysis where they investigated current studies published between 2005 and 2015 on the treatment of infrapopliteal lesions and included in the MEDLINE and EMBASE databases. The ' random-effects meta-analysis model' was used to analyze procedural (technical success, flow-limiting dissection, temporary stent placement) and long-term (primary patency, revascularization, major amputation, all-cause death) outcomes. In addition, 52 studies involving 6769 patients with 9399 lesions below the knee were included in the analysis. The technical success rate was found to be 91.1 percent.

Results in the first year were as follows: primary patency $(63.1 \%)$, re-intervention (18.2\%), major amputation (14.9\%), and all-cause mortality (15.1\%). Significant heterogeneity and bias were observed for most PTA results. In our study, during the 6th follow-up visit, 18 of 31 patients did not show symptoms, while our primary patency rate was 72.9 percent. Choosing Rutherford category 2 and 3 as the study inclusion criterion for our patients and excluding categories 4, 5, 6 may partially explain one our technical success.

Indeed, severely deteriorated vascular structure in patients with high Rutherford category could decrease our technical success rate of recanalization. Another possible reason for our high technical success may be explained by our preference for a low- profile (0.018 inches) and hydrophilic guide wire. However, in a patient with an occluded middle segment of infrapopliteal artery, unlike other patients, we could not pass beyond the occlusion during PTA using a 0.018 guide wire, but we could achieve patency using a 0.35 -inch hydrophilic guide wire. In another patient, stenosis that could not be negotiated despite all our efforts was relieved by proceeding subintimally with a 0.018 guide wire and then falling into the real lumen.

One study ${ }^{[20]}$ has shown that PTA performed for below- 
the- knee occlusions is a better alternative than a conservative or surgical approach. The results of exercise therapy are not sufficient because exercise is suitable for only a third of these patients. Vascular surgery is performed only in patients with critical leg ischemia ${ }^{[23,24]}$. In summary, the majority of patients suffering from intermittent claudication, which reduces the quality of life, benefit from endovascular therapy when no other therapeutic option is effective. Endovascular treatment has the advantage of repeated intervention even in the same vascular segment.

One of the main limitations of our study was the low number of patients. In addition, given that our follow-up period was limited to six months and lack of repeated long-term follow-ups are other limitations of our study. Current studies of PTA usedfor occluded infrapopliteal arteries generally reveal suboptimal, short-term, and 1-year clinical outcomes. However, the heterogeneity of patient populations hinders interpretation and generalization of existing findings. Procedural failures and inability to achieve patency are the main therapeutic challenges that need to be resolved. Large-scale, multicentre, prospective studies that systematically evaluate current infrapopliteal treatment methods are needed to develop contemporary and proven treatment standards.

Ethics Committee Approval: The local ethics committee of Fatih Sultan Mehmet Training and Research Hospital approved the study (30/01/2020 - 17073117-050.06).

Peer-review: Externally peer-reviewed.

Authorship Contributions: Concept: C.S.; Design: C.S., Y.Ö.; Data Collection or Processing: C.S., Y.Ö.; Analysis or Interpretation: C.S., Y.Ö.; Literature Search: C.S., Y.Ö.; Writing: C.S.

Conflict of Interest: None declared.

Financial Disclosure: The authors declared that this study received no financial support.

\section{References}

1. Balkanay OO, Ömeroğlu SN. Yaşlılarda periferik arter hastalığına yaklaşım. Turk Kardiyol Dern Ars 2017;45:96-101.

2. Hunt BD, Popplewell MA, Davies H, Meecham L, Jarrett $H$, Bate G, et al; BASIL-3 Collaborative Group. BAlloon versus Stenting in severe Ischaemia of the Leg-3 (BASIL-3): study protocol for a randomised controlled trial. Trials 2017;18:224. [CrossRef]

3. Dotter CT, Judkıns MP. Translumınal Treatment of Arterıosclerotic Obstruction. Description of a New Technıc and a Prelımınary Report of its Applıcatıon. Circulation 1964;30:65470. [CrossRef]

4. Grüntzig A, Hopff H. [Percutaneous recanalization after chronic arterial occlusion with a new dilator-catheter (modification of the Dotter technique) (author's transl)]. [Article in German].
Dtsch Med Wochenschr 1974;99:2502-10, 2511.

5. Abu Dabrh AM, Steffen MW, Undavalli C, Asi N, Wang Z, Elamin $M B$, et al. The natural history of untreated severe or critical limb ischemia. J Vasc Surg 2015;62:1642-51.e3. [CrossRef]

6. National Institute for Health and Clinical Excellence. Lower limb peripheral arterial disease. Diagnosis and management. NICE clinical guideline 147. National Clinical Guideline Centre; 2012.

7. Swaminathan A, Vemulapalli S, Patel MR, Jones WS. Lower extremity amputation in peripheral artery disease: improving patient outcomes. Vasc Health Risk Manag 2014;10:417-24.

8. Diamantopoulos A, Katsanos K. Treating femoropopliteal disease: established and emerging technologies. Semin Intervent Radiol 2014;31:345-352. [CrossRef]

9. Pastromas G, Katsanos K, Krokidis M, Karnabatidis D, Spiliopoulos S. Emerging stent and balloon technologies in the femoropopliteal arteries. ScientificWorldJournal 2014;2014:695402.

10. Mustapha JA, Finton SM, Diaz-Sandoval LJ, Saab FA, Miller LE. Percutaneous Transluminal Angioplasty in Patients With Infrapopliteal Arterial Disease: Systematic Review and Meta-Analysis. Circ Cardiovasc Interv 2016;9:e003468. [CrossRef]

11. Kudo T, Chandra FA, Ahn SS. The effectiveness of percutaneous transluminal angioplasty for the treatment of critical limb ischemia: a 10-year experience. J Vasc Surg 2005;41:423-35.

12. Karnabatidis D, Spiliopoulos S, Diamantopoulos A, Katsanos K, Kagadis GC, Kakkos S, et al. Primary everolimus-eluting stenting versus balloon angioplasty with bailout bare metal stenting of long infrapopliteal lesions for treatment of critical limb ischemia. J Endovasc Ther 2011;18:1-12. [CrossRef]

13. Davies MG, El-Sayed HF. Outcomes of Isolated Tibial Endovascular Interventions for Tissue Loss in CLI Patients on Hemodialysis. J Endovasc Ther 2015;22:681-9. [CrossRef]

14. Sigala F, Kontis E, Hepp W, Filis K, Melissas J, Mirilas P. Longterm outcomes following 282 consecutive cases of infrapopliteal PTA and association of risk factors with primary patency and limb salvage. Vasc Endovascular Surg 2012;46:123-30.

15. Hardman RL, Jazaeri O, Yi J, Smith M, Gupta R. Overview of classification systems in peripheral artery disease. Semin Intervent Radiol 2014;31:378-88. [CrossRef]

16. Ascher E, Marks NA, Hingorani AP, Schutzer RW, Nahata S. Duplex-guided balloon angioplasty and subintimal dissection of infrapopliteal arteries: early results with a new approach to avoid radiation exposure and contrast material. J Vasc Surg 2005;42:1114-21. [CrossRef]

17. Aulivola B, Gargiulo M, Bessoni M, Rumolo A, Stella A. Infrapopliteal angioplasty for limb salvage in the setting of renal failure: do results justify its use? Ann Vasc Surg 2005;19:762-8.

18. Bradbury AW, Adam DJ, Bell J, Forbes JF, Fowkes FG, Gillespie I, et al; BASIL trial Participants. Bypass versus Angioplasty in Severe Ischaemia of the Leg (BASIL) trial: An intention-to-treat analysis of amputation-free and overall survival in patients randomized to a bypass surgery-first or a balloon angioplasty-first revascularization strategy. J Vasc Surg 2010;51:5S-17S. 19. Bakal CW, Sprayregen S, Scheinbaum K, Cynamon J, Veith 
FJ. Percutaneous transluminal angioplasty of the infrapopliteal arteries: results in 53 patients. AJR Am J Roentgenol 1990;154:171-4. [CrossRef]

20. Krankenberg $H$, Sorge I, Zeller T, Tübler T. Percutaneous transluminal angioplasty of infrapopliteal arteries in patients with intermittent claudication: acute and one-year results. Catheter Cardiovasc Interv 2005;64:12-7. [CrossRef]

21. Kok HK, Asadi H, Sheehan M, McGrath FP, Given MF, Lee MJ. Outcomes of infrapopliteal angioplasty for limb salvage based on the updated TASC II classification. Diagn Interv Radiol 2017;23:360-4. [CrossRef]
22. Newman AB, Siscovick DS, Manolio TA, Polak J, Fried LP, Borhani NO, et al. Ankle-arm index as a marker of atherosclerosis in the Cardiovascular Health Study. Cardiovascular Heart Study (CHS) Collaborative Research Group. Circulation 1993;88:837-45. [CrossRef]

23. Varu VN, Hogg ME, Kibbe MR. Critical limb ischemia. J Vasc Surg 2010;51:230-41. [CrossRef]

24. Dormandy JA, Rutherford RB. Management of peripheral arterial disease (PAD). TASC Working Group. TransAtlantic Inter-Society Consensus (TASC). J Vasc Surg 2000;31:S1-S296. 